\title{
Innovative Outreach Methods for Adult Education in the 21st Century: Knowing Your Audience and Moving From the Centerpiece to the Sideline
}

\author{
By Rachel Mealor and Rachel Frost
}

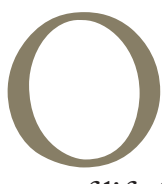
utreach has taken on various forms during the past 10 years, and because technology has become such an integral part of teaching, changes continue to occur at an even greater speed. The pace of life for educators has us reaching for the newest technology and calling ourselves innovative if we embed a YouTube video or a couple of iClicker (a participant response system that allows you to poll the participants and display the results; Macmillan, New York, NY) questions into our existing PowerPoint presentation. We plan our programs and entice participants to attend with food and Continuing Education Units (CEUs), the perpetual carrot on a string for most education programs, and hope the weather prohibits our clientele from doing something they view as more valuable. But what if our programs were viewed by people as the most valuable use of their time? How can we make that transition from a boring necessity to an investment in their future?

We believe the most critical component of an effective outreach program is knowing your participants. As educators, we have to ask ourselves: 1) what information do my clientele want or need, and 2) how does this particular group of participants want to receive the information? Once we know the answer to both parts of the equation, we can begin to discover innovative ways to meet those needs. Our purpose in this article is to challenge educators to evaluate the way they approach outreach by learning about their participants and tailoring programs specifically focused on the needs and learning styles of their clientele.

Traditionally, educators have used proven techniques, such as newsletters or popular press articles, demonstrations or field days, and communication via telephone or face-to-face interactions, to relay information to our clientele. However, there are challenges that come with these traditional educational methods, namely, time and money constraints. Budgets for Extension educators, especially in the current economy, are low and continue to decline. Furthermore, gas prices are high, and when coupled with the vast geographical areas that
Extension educators cover in most western states, traveling to workshops and field demonstration sites can become very expensive. Depending on the University Administration's priorities, educators may face increasing pressure from tenure and review committees to produce publications and obtain grant dollars for research that takes precedence over workshops and ranch visits. Ranchers and land managers are also feeling the pinch financially and usually have a full off-ranch schedule of political and agency meetings that they are required to attend, effectively limiting both money and time to travel to education opportunities.

The constraints faced by both educators and clientele have inspired the development of many new tools and technologies that can be used to assist in delivering information to our participants. Webinars can be an inexpensive and effective way to transfer information directly to a client's home at a convenient hour. If well designed, they offer opportunities for client-educator interaction and follow-up for more information. Smart phones are another new technology that has truly changed the way individuals receive information. For example, in very remote areas, it may be difficult or expensive to get high-speed Internet to the location. However, if a cellular signal is available, smart phones allow quick access to email, the Internet, and numerous applications. These features allow ranchers to stay on top of e-mail and news, even when out in the field or traveling on the road. Social networking is another tool that is not just for personal use. Professional organizations are using Twitter and Facebook to disseminate information and news flashes. Once an organization is recognized as a reputable source by clientele, the news can spread quickly over long distances with little to no added input on the part of the organization.

Nevertheless, technology is not synonymous with innovation and often the most innovative programs meld cuttingedge outreach techniques with traditional delivery methods. Although technology can stretch limited dollars and be very 
useful, the absence of physical presence can begin to degrade one's credibility. The biggest downfall of technology is that, when used alone, it can be perceived as impersonal, with the focus on the educational product, not the learners as individuals (i.e., the proverbial "tail wagging the dog").

As educators, we need to put the focus on our clientele and their needs, rather than our product or ourselves. Before developing a program, we should ask the following:

1) How can we, as educators, offer valuable learning opportunities that provide clientele with the tools they need to improve their management practices?

2) How can we develop and deliver educational programs that will help participants to understand, retain, and apply skills, knowledge, and attitudes that will enrich their lives?

One important aspect of this process is to ensure that program planning is based on the participation of the constituents, not based on the feelings of staff or educators. ${ }^{1}$ How often do we, as educators, develop educational materials based on our participants' needs and present it in a way that will be clearly understood and retained rather than presenting the same old information from PowerPoint slides? As you think about this, ask yourself, how do I like to learn? Some of us enjoy sitting in front of the teacher and gathering information by listening. However, many of us retain information much more readily through participating in an activity or solving a problem using the techniques and skills the teacher provides. Do we educate that way? Do we consider our participants' educational needs and learning styles before developing our material?

To design an educational program around the needs and learning styles of the clientele, it is important to gather specific information about the clientele before presenting the program. This can be done well in advance by querying the organizer of the educational event for information such as the following: What is the purpose of the event? Who was directly invited to the event? What mediums were used to advertise the event? This should give you some broad clues about the age range of the participants as well as their profession and interests. Communication with potential event organizers can facilitate the gathering of this information in advance through questions on the registration documentation or personal inquiries as to the clientele's existing knowledge on a topic. For many outreach efforts, this is difficult; however, you can still gather some information on site. Asking a few questions at the beginning of your program can give you insight as to the participants' experiences, areas of interest, and goals for attending the education event. This will help you align your message to their expectations for the program. As much as possible, encourage participation within the program by periodically stopping to ask for questions, comments, or personal experiences at key points. Most people are not willing to interrupt a speaker who is on a roll, and their question may get lost if you expect the participants to hold questions until the end. You will have to manage time and

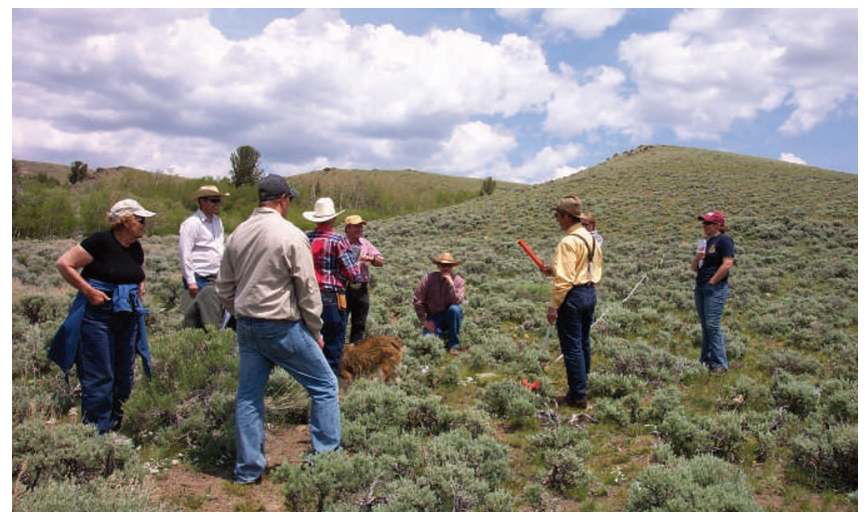

Adults learning about rangeland vegetation monitoring through hands-on experience at a University of Wyoming Extension workshop. Photo courtesy of Rachel Mealor.

the conversation to keep it focused, but this can provide some excellent opportunities to connect with your participants by demonstrating your respect for their opinions and experiences and a genuine concern for their learning experience.

In general, people prefer to learn by one of three different ways; by hearing (auditory), seeing (visual), or by doing (kinesthetic or tactile). ${ }^{2}$ Because your participants will most likely have a mix of learning types, you should present the key points of your topic audibly and visually, as well as engaging the participants in a "doing" activity, which solidifies the take-home message, such as group discussions, role playing, or actual hands on in the field. Catering to the three major learning styles will promote participant engagement, at least for a portion of the time, and result in greater retention of material. Creative thinking may allow you to ask a question that can provide information on how your participants learn as well as what their current state of knowledge is and what they find most interesting about your topic. You may want to consider using "clickers," depending on the sensitivity of what you are asking, to encourage participation and truthful answers. Now, you have the ability to adjust how you present your material for the specific participants, even if it is as simple as skimming over certain aspects and spending more time on areas that are important or interesting to that particular group of participants. Outreach is not about making our participants learn a specific thing, but rather innovative, effective outreach centers on connecting with the participants, so they realize the value of continuing education and seek us out for information.

Let us consider adult learners for a moment and what we know about how they receive and retain new material. Adult learners have accumulated a wealth of experiences, and they are shaped by those experiences. Consequently, they can become frustrated when their experience is not a factor in learning, and they are often more judgmental. Adult learners engage more with information that is presented as an immediate problem or need that must be solved. If the relevancy of the information is not immediately clear to adult learners, they will often discontinue a program. ${ }^{1,3}$ As educators, 


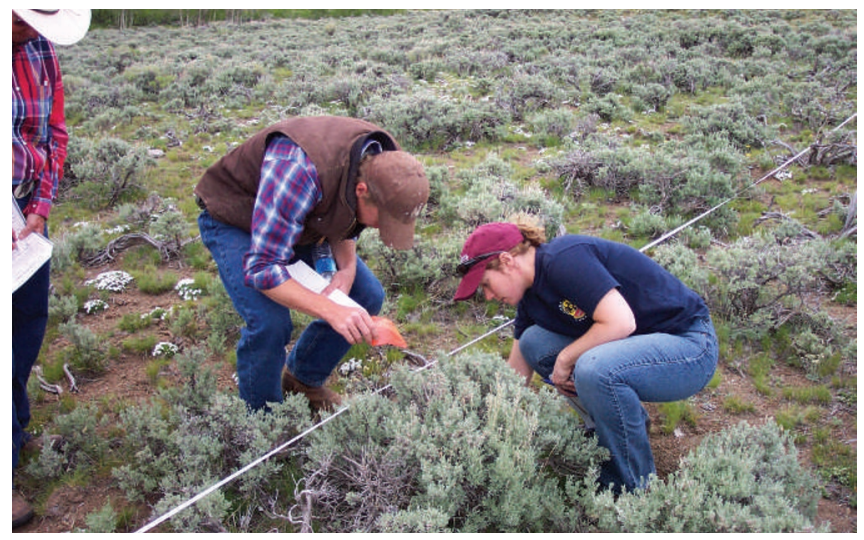

Adults learn better through actively participating in the process. These participants are collecting monitoring data as a group and learning how to work through the process on their own with an instructor available as a guide. Photo courtesy of Rachel Mealor.

we need to do a better job of connecting with our clientele via their diverse experiences, backgrounds, education, and interests. A word of caution for anyone involved in adult outreach: Never underestimate the knowledge of your participants!

So, how do we tailor a program that can embrace this diversity and empower people to use their experiences to make decisions and solve problems? This question is especially critical for rangeland problems, where so many variables are specific to the site or situation. Put simply, instructors need to move away from being the "sage on the stage" to being the "guide on the side." Our world is changing much too quickly to rely solely on traditional methods of instruction, and learners have to be taught how to adapt to new information and remain lifelong learners. ${ }^{1}$ To meld these complementary objectives, we believe that educators must "seek first to understand, then to be understood" (Steven Covey), as the guide on the side, rather than clinging to and regurgitating what is familiar and comfortable as the sage on the stage. If clientele can quickly identify with the material being presented in educational programs as relevant to their own personal experiences and impending problems, they will be more willing to embrace the tools (both new and old) that instructors provide them. Moreover, participants will be better equipped to solve future problems and to continue to seek out Extension and other outreach programs as a primary means to satisfy their desire for lifelong, experiential learning.

A case study can help illustrate these points. The High Plains Ranch Practicum ${ }^{4}$ is a program that is taught jointly by the University of Wyoming Extension and Nebraska Extension. This ranch management school encompasses 8 days, and the course goes from June through January. The dates were selected to provide participants experience seeing ecological systems throughout the entire growing season. There is a tuition fee, but scholarships are usually available if certain exercises and tasks are completed by the end of the school. There have been six classes to date and around 125 graduates of the school. The focus areas of the practicum are range and forage, ranch economics through enterprise analysis, livestock nutrition and reproduction, and family working relationships and personnel management. The school takes an integrated, systems approach to ranch management and focuses on profit-centered strategies and hands-on application of the material. There are very few PowerPoint lectures, with more emphasis on applicable exercises to illustrate the information being taught. The educators focus on relevant issues facing producers with a problem-solving-based approach. So, why is this school seeing success? Quite simply, the information being presented is relevant, there is continual dialogue during which participants are asked if they are getting what they came to the school for, and the activities are experiential, practical, and realistic. ${ }^{1}$ Former ranch-practicum participants indicated that because of knowledge gained, 95\% would use decision-making skills gained from the school to help them make management decisions. Survey respondents indicated knowledge gained would, on average, increase profits by $\$ 38.00$ per head of cattle managed. One of the participants commented, "The topics that were covered were very relevant to the time of the economy that we are in as ranchers and opened people's eyes to different ideas and resources."

As educators, we should ask ourselves, are we doing this with our programs? Are our programs technologically innovative or are they merely innovatively technological? We believe true innovation starts with knowing the participants and progresses to the way we make the information available, relevant, and useful to our participants. Tailoring programs to our participants' educational needs and their style of learning requires more work, but the reward for the client can be tremendous. For example, adoption of new educational technology or new material requires a considerable time investment on the part of the instructor. New products and tools come with a learning curve and, admittedly, will push many of us out of our comfort zones. But for those who would like to try some new teaching tools, consider Prezi (Prezi Inc, San Francisco, CA $)^{i}$ in lieu of Power Point. Prezi is an open-source, cloud-based presentation program that allows for a nonlinear approach to teaching while still providing great visual aids. ${ }^{5}$ With this program, you can access slides about topics as they come up in discussion, not as you originally ordered them in Power Point. This type of presentation requires organization from the author, but can be very effective for adaptive material to fit the participants' interests and knowledge level. Such nonlinear programs can also help educators avoid the embarrassing "slide-skipping syndrome," when we have to flip quickly though the remainder of our slides to the final take-home message because we ran out of time. A word of caution: Be very familiar with any new program before using it in front of participants. Your unfamiliarity and frustration with a new product or concept will be greatly compounded in your participants and will dramatically lower the effectiveness of your presentation or program. Remember, change is scary,

'Prezi, http://prezi.com. 
but if we expect our clientele to change their management based on our message, shouldn't we be willing to change our education based on our clientele?

Taking the time to know our participants, their level of knowledge, and their style of learning greatly increases the reward for the clients. The Range Management School for Ranchers is a prime example of how participant input in the early stages of an educational program can produce real, lasting benefits for the participants. ${ }^{6}$ The era of the 1990s was a stressful, uncertain time for public-land ranchers in Colorado, so they sought the help of the Colorado Extension Service to assist them in becoming better land managers. The Extension Service responded by asking 18 producers to help develop the curriculum to ensure that the educational experience met the educational needs of the participants. Robbie Baird Levalley, Livestock and Range Specialist for the Tri-River Area, Colorado State University Extension, summed up the producers requests for education as follows: "They wanted details. They did not want the basics; however, they also did not want to be overwhelmed with scientific jargon.... They wanted information that would help them defend their livelihood." The organizers followed the requests of the producers and developed two Range Management Courses that were open to ranchers, agency personnel, and environmentalists. At the conclusion of the course, the organizers asked participants to comment on the course. As a result, some topics were deleted, allowing the course to be condensed; however, it still maintained classroom instruction, field tours, and practical application to serve all learning types. The participant-centered approach to the school has had significant impacts on the attitudes and resulted in actual management changes by most (ca 70\%) of the participants. Changes in management are making a difference on the ground, and the cooperative nature of the school has improved relationships between the federal land management agencies and permittees. The ranching community feels more stable, and there is a pervasive win-win attitude, where once conflict ruled the rangeland. ${ }^{6}$ The model was so successful that they developed a new course designed by and for agency personnel of all disciplines to introduce them to grazing and the potential use of livestock to manage the landscape. The target audience included all specialists from Colorado Parks and Wildlife, National Park Service, Bureau of Land Management, rangeland consultants, US Forest Service, universities, and Natural Resources Conservation Service, as well as the livestock industry. Topics for the course included plant growth, timing and duration of grazing, disturbance-driven ecosystems, factors that cannot be controlled by livestock, limitations of research on landscapes, managing livestock for vegetation manipulation, range nutrition and animal behavior, rangeland monitoring, and the National Environmental Policy Act. The course was held in Montrose, Colorado, in February of 2012. There were 76 participants in the class, and they represented the full scope of the targeted audience. Future plans include a presentation to regional directors of the US Forest Service and expanding the school to other region-2 forests.
Both of the range schools that we describe in this article are examples of participatory learning, which leads to empowerment, allowing people to carry out their own analysis, make their own decisions, and organize their own activities. ${ }^{1}$ This empowerment carries over to other areas of their lives and makes them desire to be lifelong learners. Confidence derived from their ability to solve problems creates an attitude change that, when coupled with increased knowledge, leads to changes in behavior, which is the ultimate goal for most outreach efforts. Clearly, as educators, we should be challenged to change from intellectual sage on the stage to resourceful guide on the side to produce real and sustained effects from our programs. We were certainly challenged to change our teaching and outreach strategy by writing this article.

\section{Acknowledgments}

The authors would like to thank Stan Skrabut, Instructional Technology Educational Specialist, and Dallas Mount, Southeast Area Livestock Extension Educator, both at the University of Wyoming. Stan was very helpful in providing insight into adult learning references, and Dallas provided information regarding the High Plains Ranch Practicum. We also wish to thank Dr John Paterson, Beef Cattle Extension Specialist, and Tommy Bass, Livestock Environmental Specialist, both at Montana State University, for sharing their thoughts on what it means to be a high-tech extension specialist.

\section{References}

1. Knowles, M. 1980. The modern practice of adult education: from pedagogy to andragogy. Englewood Cliffs, NJ, USA: Prentice Hall/Cambridge. 400 p.

2. Fleming, N. D. 2001. Teaching and learning styles: VARK strategies. Christchurch, New Zealand: N. D. Fleming.

3. Vella, J. 2002. Learning to listen, learning to teach: the power of dialogue in educating adults. San Francisco, CA, USA: Jossey-Bass. 288 p.

4. High Plains Ranch Practicum. 2010. The High Plains Ranch Practicum: providing ranchers a system approach to decision making in the complex and exciting business of ranching. Available at: http://hpranchpracticum.com. Accessed 23 January 2012.

5. Prezi. 2012. Prezi: make your presentations zoom. Available at: http://www.prezi.com. Accessed 10 March 2012.

6. LeValley, R. B., J. Murray, F. Reed, J. Hawks, and D. BradFORD. 2000. Range management schools for ranchers: or how to teach plant phenology, forage use, plant physiology and other esoteric range management concepts to a bunch of cowboys. Rangelands 22(4):10-13.

Authors are Rangeland Extension Specialist, Dept of Ecosystem Science and Management, University of Wyoming, Laramie, WY 82071,USA,rdmealor@uwyo.edu (Mealor); and Research Scientist, Dept of Animal and Range Sciences, Montana State University, Bozeman, MT 59717-2900, USA, frost@montana.edu (Frost). 